\title{
Contaminação de queijo Minas frescal por bactérias patogênicas: um risco ò saúde
}

\section{Contamination of Minas frescal cheese by pathogenic bacteria: a health risk}

\author{
Katia P. Vieira ${ }^{1}$; Meire M. Ledesma ${ }^{2}$; Clóudia M. Rosa ${ }^{3}$; Regina H. Hassegawa ${ }^{4}$ \\ 1 Farmacêutica e Bioquímica - Uninove. \\ 2 Mestre em Ciência - ICB/USP; Pesquisadora do grupo Microbiologia de Alimentos e Professora - Uninove. \\ 3 Doutora em Ciências dos Alimentos - FCF/USP; Pesquisadora do grupo Microbiologia de Alimentos e Coordenadora do curso de \\ Farmácia e Bioquímica - Uninove. \\ 4 Doutora em Ciências - ICB/USP; Pesquisadora do grupo Microbiologia de Alimentos, Professora e Coordenadora Adjunta do curso \\ de Farmácia e Bioquímica - Uninove.

\section{ENDEREÇO PARA CORRESPONDÊNCIA} \\ Regina H. Hassegawa \\ Rua Margarida C. Alves de Proença, 190 apto 41, Jd Rizzo \\ 05587-140 - São Paulo - SP [Brasil] \\ E-mail: \\ kakapvieira@yahoo.com.br
}

\begin{abstract}
RESUMO
Neste artigo, será discutida a contaminação do queijo Minas frescal por bactérias que podem causar toxinfecção alimentar, cujos sintomas podem ser diarréia, vômitos, febre, flatulência e até aborto. O queijo Minas frescal, assim como outros alimentos, é fabricado com leite cru, que favorece o crescimento e a presença de um elevado número de bactérias patogênicas como Staphylococcus aureus, Salmonella spp., Shigella spp., Escherichia spp. e Listeria spp. O controle de contaminação microbiana e as boas práticas de fabricação desse queijo são de grande importância para a saúde pública, pois esse produto é muito consumido pela população.

Descritores: Bactérias patogênicas; Diarréia; Intoxicação alimentar; Queijo Minas frescal.

ABSTRACT

In this article, it will be discussed the contamination of Minas frescal cheese by bacteria that can cause food toxinfection, which symptoms can be diarrhea, vomit, fever, flatulence, even abortion. Foods such this cheese is made from raw milk, that make possible growth and presence of a large number of pathogenic bacteria such as Staphylococcus aureus, Salmonella spp., Shigella spp., Escherichia spp., Listeria spp. The control of microbial contamination as well as good manufacturing practices of this cheese is important to public health, since this product is consumed by population.
\end{abstract}

Key words: Diarrhea; Food poisoning; Minas frescal cheese; Pathogenic bacteria. 


\section{INTRODUÇÃO}

A maioria dos casos de intoxicação e infecção alimentar no homem é atribuída a bactérias patogênicas como Salmonella spp., Staphylococcus aureus, Clostridium botulinum, Escherichia spp. e Shigella spp. Nos últimos anos, houve crescente interesse em identificar as causas de doenças gastrintestinais humanas e também as enterotoxinas e os fatores de virulência causadores de doença ${ }^{1}$.

Um dos alimentos que podem causar toxinfecção em humanos é o queijo Minas frescal, quando contaminado por bactérias patogênicas, em razão das péssimas condições de higiene nas quais é produzido e comercializado. A contaminação microbiana do queijo pode ser clandestina, gerada pela ordenha feita manualmente em currais ${ }^{2}$.

O queijo Minas frescal é um produto artesanal de grande aceitação, consumo e produção em quase todo o país. Feito de massa macia branca, com alto teor de umidade, sem maturação, deve ser consumido nos primeiros quinze dias após sua fabricação ${ }^{3}$. O consumo desse tipo de queijo teve aumento significativo na década de 80 , por se tratar de um produto de fácil elaboração e de baixo custo ${ }^{4}$.

Este estudo foi realizado com o objetivo de elaborar um levantamento bibliográfico sobre a contaminação de queijo Minas frescal por bactérias patogênicas e toxinfecção alimentar, pois, apesar das exigências das boas práticas de fabricação, como a pasteurização do leite, a higienização adequada dos utensílios e do manipulador, muitas vezes o queijo é preparado artesanalmente e não atende a essas especificações, contribuindo para a má qualidade do produto e para pôr em risco a saúde humana.

\section{LEITE COMO MATÉRIA-PRIMA}

O leite é uma emulsão de óleo em água estabilizado por proteínas, produzido pelas glândulas mamárias de animais ${ }^{5}$. A composição do leite normal apresenta lipídeos, responsáveis pelo sabor e aroma do leite, carboidratos, minerais como cálcio e fósforo e vitaminas como tiamina, vitaminas A, E, D e $80 \%$ de água 6 .

Em relação ao tratamento térmico, o leite pode ser cru, pasteurizado ou esterilizado, e em relação à quantidade de gordura, integral, semidesnatado ou desnatado ${ }^{6}$.

O leite recém-ordenhado, em condições mínimas de assepsia, contém $5,0 \times 10^{3}$ a $5,0 \times 10^{4}$ $\mathrm{UFC} / \mathrm{mL}$, devendo ser coletado, resfriado e mantido sob boas condições de higiene para eliminação de microrganismos. Outra maneira de eliminá-los é por meio da pasteurização e a esterilização ${ }^{7}$.

A qualidade inicial do leite é a primeira condição para obter um bom queijo. Quando o número de bactérias patogênicas iniciais do leite é elevado, os processos de beneficiamento e industrialização, em geral, não são eficientes para sua destruição. $\mathrm{O}$ crescimento de bactérias no leite pasteurizado está relacionado com as condições em que o produto é armazenado antes de chegar aos consumidores. A manutenção desse produto em temperatura superior à indicada pelo Regulamento da Inspeção Industrial e Sanitária de Produtos de Origem Animal (RIISPOA) pode ser fator determinante para que não obedeça aos padrões microbiológicos recomendados ${ }^{8}$.

Apesar de a legislação brasileira exigir a utilização de leite pasteurizado no preparo de queijo Minas frescal, é bastante freqüente a comercialização do produto que não atende a essa especificação legal ${ }^{9}$.

\section{PRODUÇÃO DO QUEIJO MINAS FRESCAL}

O queijo Minas frescal é tradicionalmente produzido com adição de coalho no leite cru, podendo-se adicionar previamente a ele, o fermento lático, um componente importante para o controle do desenvolvimento da microbiota contaminante $\mathrm{e}^{10}$.

A aplicação do fermento no início do processamento do queijo é uma forma de aumentar a 
acidez, diminuindo a multiplicação de microrganismos patogênicos ${ }^{11}$.

O desenvolvimento da cultura lática favorece a produção contínua e controlada do ácido lático, o que dificulta a proliferação de microrganismos indesejáveis, além de proporcionar melhores condições para a atuação do coalho e facilitar a expulsão do soro ${ }^{12}$.

Quando esse produto é fabricado de forma artesanal, pode ocorrer a contaminação por diversos microrganismos, o que compromete sua qualidade e a segurança da saúde do consumidor. Dessa forma, práticas de higiene devem ser observadas para prevenir uma possível contaminação do produto. Além disso, por não ser maturado, é perecível, devendo ser consumido rapidamente, após curta estocagem em ambiente refrigerado ${ }^{13}$.

\section{INTOXICAÇÃO E INFECÇÃO ALIMENTAR}

As bactérias patogênicas podem produzir doenças tanto por sua capacidade de multiplicação e disseminação nos tecidos quanto pela produção de toxinas. As doenças microbiológicas de origem alimentar são divididas em duas grandes categorias: a intoxicação, causada pela ingestão de alimentos contendo toxinas microbianas pré-formadas, produzidas durante a intensa proliferação dos microrganismos patogênicos no alimento. Nesse grupo, estão as bactérias Clostridium botulinum, Staphylococcus aureus, Bacillus cereus e os fungos produtores de micotoxinas como Aspergillus spp., Penicilium spp. e Fusarium spp. ${ }^{1}$, e a infecção, decorrente da ingestão de alimentos contendo microrganismos viáveis, que aderem à mucosa do intestino humano e proliferam, colonizandoo e invadindo os tecidos, ou ainda produzindo toxinas que alteram o funcionamento das células do trato intestinal. Entre essas bactérias invasivas destacam-se a Salmonella spp, a Shigella spp., a Escherichia spp. e a Yersinia enterocolitica ${ }^{1}$.

As doenças de origem alimentar têm sido motivo de crescente preocupação dos órgãos de saúde pública. No Brasil, apesar das limitações do sistema de informação, há registros de que a toxinfecção alimentar causou a internação de 26.588 pessoas, em 2000. Esse número alerta para o perigo da contaminação alimentar, responsável por internação e aponta para a necessidade da segurança alimentar na saúde pública ${ }^{14}$.

Os alimentos comumente implicados na diarréia de origem alimentar são carnes, saladas, leite e derivados, entre os quais o queijo. A transmissão ocorre pelo consumo de alimento contaminado por bactérias patogênicas, em razão da manipulação inadequada na preparação do alimento ${ }^{15}$.

Os sintomas da doença entérica são principalmente diarréia, vômitos, febre, cólica abdominal, náuseas, flatulência e indisposição. A prevenção e o controle dessa doença dependem da vigilância dos serviços de saúde e da educação para os conceitos de segurança alimentar ${ }^{1}$.

\section{CONTAMINAÇ̃̃O DO QUEIJO MINAS FRESCAL}

A produção do queijo Minas frescal, quando realizada artesanalmente por pessoas não treinadas, pode comprometer não só o produto, mas também a saúde dos indivíduos, pois é possível que contenha bactérias patogênicas como o Staphylococcus aureus e suas enterotoxinas, entre outros microrganismos. Sabioni et al. ${ }^{16}$ relataram surtos de intoxicação alimentar em julho de 1987, em Ouro Preto - MG, provocados pelo consumo de queijo Minas frescal contaminado por $S$. aureus e coliformes fecais. Em razão do aparecimento dos sintomas como diarréia, febre, náuseas, vômitos e indisposição, concluiu-se que o surto foi provocado pela presença da bactéria $S$. aureus. No município de Cuiabá - MT, onde a contagem das colônias foi de $10^{5} \mathrm{UFC} / \mathrm{g}^{17}, 40$ \% das amostras de queijo estavam contaminadas por S. aureus. Gomes et al. ${ }^{18}$ encontraram de $4,7 \times 10^{4}$ a $1,4 \times 10^{6} \mathrm{UFC} / \mathrm{g}$ de $S$. aureus em queijo Minas frescal comercializado em Piracicaba - SP. Almeida Filho e Nader $^{19}$ investigaram a presença de $S$. aureus em 80 amostras de queijo tipo Minas frescal, 
produzidas artesanalmente e comercializadas em Poços de Caldas - MG, e verificaram que 40 amostras (50\%) revelaram valor médio em torno de $10^{5} \mathrm{UFC} / \mathrm{g}$. Todos esses resultados são preocupantes, pois os valores estão acima do limite máximo permitido, de $10^{3} \mathrm{UFC} / \mathrm{g}$, estabelecido pelo Ministério da Saúde, o que é suficiente para gerar um surto de intoxicação alimentar.

A intoxicação provocada pela ingestão de alimentos contaminados pelas enterotoxinas (A, B, C, D, E e F), produzidas pelo $S$. aureus, pode causar ação emética e diarréica nos humanos. Essas enterotoxinas são proteínas termorresistentes. Embora com a pasteurização do leite o S. aureus seja destruído, não há inativação das enterotoxinas ${ }^{1,20}$. Santos e Genigeorgis ${ }^{21}$ estudaram a capacidade de $S$. aureus sobreviver e produzir enterotoxina no queijo Minas frescal. Observaram que a contagem dessa bactéria foi maior que $10^{6} \mathrm{UFC} / \mathrm{mL}$ em 57,44\% dos queijos, feitos com leite pasteurizado, e as toxinas A, B e C foram detectadas em $62,5 \%$. Loguercio e Aleixo $^{22}$ avaliaram a contaminação de 30 amostras de queijo Minas frescal produzidas em Cuiabá e observaram que 29 delas (96,67\%) apresentaram contaminação por Staphylococcus aureus, e 28 (93,33\%), por Escherichia coli .

O grupo das bactérias coliformes totais e fecais é de grande importância, pois muitas delas colonizam o trato intestinal de animais e seres humanos, sendo, por isso, utilizadas para a verificação da qualidade sanitária dos alimentos $^{23}$. A bactéria Escherichia coli e os enterococos são os mais pesquisados em alimentos. Oliveira et al. ${ }^{24}$ analisaram 32 amostras de queijo Minas frescal de seis fábricas de laticínios na região noroeste do Estado de São Paulo e verificaram que, em $94 \%$ das amostras, foi detectada população de coliformes fecais acima do limite estabelecido pelas legislações. A resolução RDC 12/01 diz que o limite intermediário aceitável de contaminação por $E$ coli é de, no máximo, $10^{3} \mathrm{UFC} / \mathrm{g}$, e de cinco amostras, somente duas podem conter esse valor por contagem em placa ${ }^{25}$. Uma outra técnica é a de Número Mais Provável (NMP) que permite estimar a densidade de microrga- nismos viáveis presentes em uma amostra a ser analisada.

Almeida et al. $^{7}$ encontraram população média de 2,9×103 (NMP) de coliformes fecais (Escherichia coli.) em 15 amostras de queijo Minas frescal submetidas à inspeção federal, comercializados em Cuiabá - MT. Leite ${ }^{15}$, avaliando amostras de queijo Minas frescal fabricado em três indústrias de laticínios, no município de Lavras - MG, detectou população de coliformes fecais de $10^{6}(\mathrm{NMP}) / \mathrm{g}$ acima do limite máximo permitido, que é de $10^{2} / \mathrm{g}^{26}$.

Rocha et al. ${ }^{27}$ verificaram que o queijo Minas frescal, vendido em supermercados na cidade de São Paulo, apresentava número de Escherichia coli acima do limite da legislação. Três a quatro amostras de queijo de cada marca foram analisadas após 7, 14 e 21 dias da data de fabricação, descrita na embalagem. Em razão da grande umidade, o queijo se deteriorou rapidamente e o produto tornou-se impróprio após 21 dias de fabricação, porém seis marcas analisadas estavam impróprias em sete dias.

Bulhões Rossi e Júnior ${ }^{28}$ analisaram 160 amostras de queijo Minas frescal artesanal, adquiridas no comércio varejista dos municípios de Poços de Caldas (MG) e Jaboticabal (SP), para identificar a ocorrência de bactérias do gênero Aeromonas spp. Por meio dessa análise, verificaram a contaminação em 82 amostras $(51,2 \%)$ pela bactéria Aeromonas spp., que variou de $5,0 \times 10^{3}$ a $4,0 \times 10^{5} \mathrm{UFC} / \mathrm{g}$.

Das 21 marcas de queijo Minas frescal analisadas pelo Inmetro ${ }^{29}$ e comercializadas no país, sete foram reprovadas por apresentar contaminação por bactérias patogênicas; cinco, por coliformes fecais (Escherichia spp.), e duas, por Staphylococcus aureus. Uma delas ainda apresentou contaminação por Listeria spp. De acordo com a RDC12/01, amostras de queijo Minas frescal não podem conter a presença de Listeria monocytogenes, pois a ingestão de alimentos contaminados por essa bactéria pode causar infecção alimentar, cujos sintomas são náuseas, vômitos e febre, e levar recém-nascidos e imunodeprimidos à morte. Casarotti et $a l .{ }^{30}$ detectaram a 
presença de L. monocytogenes em queijo Minas frescal comercializado em Piracicaba-SP. Em 103 amostras de vários tipos de queijos produzidos no Rio de Janeiro, encontraram L. monocytogenes $(10,68 \%)$, L. innocua $(12,62 \%)$, L. grayi $(5,83 \%) \mathrm{e}$ L. weshimeri $(0,97 \%)$, e observaram alta incidência de L. monocytogenes em queijo Minas frescal $(41,17 \%)^{31}$.

Silva et al. ${ }^{32}$ estudaram a ocorrência de Listeria spp. nos pontos críticos de produção do queijo Minas frescal. De 218 amostras coletadas durante a produção, 13 foram positivas: 9 amostras para Listeria innocua; 2 para Listeria grayi e 2 para L. monocytogene. Os pontos críticos detectados foram a recepção do leite, a pasteurização, a coagulação e a estocagem.

A presença dessas bactérias acima dos limites estabelecidos na legislação indica manipulação incorreta e condições higiênicas inadequadas durante o processo de produção. Para diminuir a contaminação microbiana, a Portaria SVS/MS no 326, aprovada em 30 de julho de 1997, regulamenta processos técnicos sobre as condições higiênico-sanitárias e as boas práticas de fabricação para estabelecimentos produtores de alimentos ${ }^{33}$, porém muitas vezes não é seguida.

\section{CONCLUSÃO}

A toxinfecção alimentar é causada por microrganismos patogênicos indesejáveis, presentes nos alimentos. O queijo contaminado por bactérias como Staphylococcus aureus, Escherichia spp., Aeromonas spp., Salmonella spp. e Listéria spp. é um produto capaz de causar a toxinfecção alimentar. Essa contaminação pode ser decorrente da matéria-prima do leite ou da falta de higiene durante a produção e de condições adequadas durante o armazenamento do queijo Minas frescal.

Para diminuir os riscos de contaminação, é recomendável que o leite passe por um processo de pasteurização e que ainda seja implantado o programa de segurança alimentar do tipo Análise de Perigo e Pontos Críticos de Controle (APPCC) ou Hazard Analyis and Critical Control Points (HACCP). Esse sistema verifica a necessidade de produzir alimentos mais seguros, pois uma maneira sistematizada de estabelecer pontos de monitoramento é que garante a segurança do produto final em uma linha específica de produção.

É necessário maior atenção das autoridades sanitárias em relação à autorização de funcionamento de produção e comercialização desse produto, uma vez que a ingestão de queijo Minas frescal contaminado por bactérias patogênicas e toxinas pode causar sérios riscos à saúde humana.

\section{REFERÊNCIAS}

1. Franco BDGM, Landgraf M. Microbiologia dos alimentos. São Paulo: Atheneu; 2005.

2. Carvalho EP de. Microbiologia de alimentos, saúde pública e legislação. Lavras: UFLA/FAEPE; 2001.

3. Hoffman FC, Silva JV da, Vinturim TM. Qualidade microbiológica de queijo tipo Minas frescal, vendido em feiras livres em São José do Rio Preto-SP. Higiene Alimentar. 2002;16(96):69-76.

4. Pinto PSA, Germano MIS, Germano PML. Queijo Minas:problema emergente da vigilância sanitária. Higiene Alimentar. 1996;10(44):22-35.

5. Abreu LR de. Tecnologia de leite e derivados. Lavras: UFLA/FAEPE;1999.

6. Prata LF. Fundamentos de ciência do leite. Jaboticabal. São Paulo:Faculdade de Ciências Agrárias e Veterinárias, UNESP;1998.

7. Almeida ESF, Sigarini CO, Ferreira MB. Perfil microbiológico de queijo tipo Minas frescal de produção artesanal e inspecionada, comercializado no município de Cuiabá-MT. Higiene Alimentar. 2002;16(92/93):51-58.

8. Hoffman FL. Microbiologia do leite tipo C comercializado na região de São José do Rio Preto-SP. Higiene Alimentar. 1999;13(65):51-4.

9. Pereira ML, Lara MA, Dias RS, Carmo LS. Intoxicação por Staphylococcus aureus provocada por queijo "tipo Minas". Rev Microbiol. 1991;22:349-50.

10. Lourenço Neto JPM. Minas frescal:uso de culturas láticas como alternativa de melhoria de qualidade. Indústria de laticínios. 2000;4(2):76-9.

11. Alves VS, Costa PS da, Robbs PG, Favarin V. Avaliação tecnológica sobre a produção artesanal de queijo Minas frescal utilizando glucona-delta-lactona(GDL), e sua importância de Staphylococcus aureus. Higiene Alimentar. 2003;17(107):27-31. 
12. Bonassi IA, Goldoni JS, Lima VA. Efeito na acidificação direta com ácido lático na fabricação do queijo Minas frescal. Rev Bras de Tecnol. 1980;9:73-4.

13. Silva CAM, Leitão MF de F. Influência da temperatura de armazenamento na proliferação microbiana e no tempo de vida útil de queijo tipo "Minas Frescal". In:Congresso Brasileiro de Ciência e Tecnologia de Alimentos, 4, 1980, Rio de Janeiro. Programa Oficial, Resumos:Sociedade Brasileira de Ciência e Tecnologia de Alimentos, 1980.

14. Ministério da Saúde. Sistema de informação hospitalar - DATASUS - Ministério da Saúde, 1999. [acesso em mar 2006]. Disponível em:http://portal. saude.gov.br/saude.

15. Leite RL. Avaliação da qualidade de queijo minas padrão elaborados com leite de vaca [dissertação]. Lavras:UFLA, 2000.

16. Sabioni JG, Hirooka EY, Souza MLR. Intoxicação alimentar por queijo minas contaminado com Staphylococcus aureus. Rev Saúde Pública. 1988;22(5):23-31

17. Wendpap LL, Rosa OO. Presença de Staphylococcus em queijo Minas frescal consumido no município de Cuiabá-MT. Higiene Alimentar. 1993;7(27):23-9.

18. Gomes HA, Gallo CR,. Ocorrência de Staphylococcus aures e a produção de enterotoxina por linhagem isolada a partir de leite cru, leite pasteurizado tipo C e queijo Minas frescal comercializado em Piracicaba-SP. Cienc Tecnol Aliment. 1995;15(2):158-61.

19. Almeida Filho ES, Nador Filho A. Ocorrência de Staphylococcus aures em queij tipo "frescal". Rev Saúde Pública, 2000;34(6):578-580.

20. Fueyo JM, Martin MC, González-Hevia MA, Mendonza MC. Enterotoxin prouction and DNA fingerprinting in Staphylococcus aureus isolated from human and food sample. Relation between genetic types and enterotoxin. Int J Food Microbiol. 2001;67:139-45.

21. Santos EC, Genigeorgis C. Survival and growth of Staphylococcus aureus in commercially manufactured Brazilian Minas cheese. J Food Prot. 1981;44:177-84.

22. Loguercio AP, Aleixo JAG. Microbiologia de queijo tipo frescal produzido artesanalmente. Ciência Rural. 2001;31(6):1063-7.

23. Calci KR, Burkhardt W, Watkins WD, Rippey SC. Occurrence of male-specific bacteriophage in fecal and domestic animal wastes, human feces and human-associated wastewaters. Applie and Envir Microbiol. 1998;64(12):5027-29.
24. Oliveira CAF de, et al. Características químicas e microbiológicas de queijo Minas frescal produzidos em algumas fábricas de laticínios do estado de São Paulo-SP. Higiene Alimentar. 1998;12(55):31-5.

25. Ministério da Saúde. Agência Nacional de Vigilância Sanitária(ANVISA). Resolução- RDC n ${ }^{\circ} 12$ e 2 de janeiro de 2001. Regulamento técnico sobre padrões microbiológicos para alimentos. Diário Oficial da União. 2 jan 2001.

26. Ministério da Saúde. Agência Nacional de Vigilância Sanitária de Alimentos. Portaria n 451 de 19 de setembro de 1997. Padrões microbiológicos para produtos expostos à venda ou de alguma forma destinados ao consumo. Diário Oficial da União. 22 dez. 1997.

27. Rocha JS, Buriti FCA, Saad SMI. Condições de processamento e comercialização de queijo-de-minas frescal. Arq Bras Med Vet Zootec. 2006;58(2):263-72.

28. Bulhões CCC, Rossi Júnior OD. Ocorrência de bactérias do gênero aeromonas em queijo-deminas frescal artesanal. Arq Bras Med Vet Zootec. 2002;54:320-4.

29. Instituto Nacional de Metrologia, Normatização e Qualidade Industrial(INMETRO). [acesso em maio 2006]. Disponível em:http://www.inmetro.gov.br/ noticias.

30. Casarotti VT, Gallo CR, Camargo R. Occurrence of Listeria monocytogenes in raw milk, pasteurized type $\mathrm{C}$ milk and minas frescal cheese commercialized in Piracicaba-São Paulo. Arch Latinoam Nutr. 1994;44(3):158-63.

31. Da Silva MC, Hofer E, Tibana A. Incidence of Listeria monocytogenes in cheese produced in Rio de Janeiro, Brazil. J Food Prot. 1998;61(3):354-6.

32. Silva IM, Almeida RC, Alves MA, Almeida PF. Occurrence of Listeria spp. in critical control points and the environment of Minas Frescal cheese processing. Int J Food Microbiol. 2003;81(3):241-8.

33. Ministério da Saúde. Agência Nacional de Vigilância Sanitária de Alimentos. Portaria no 326 de 31 de julho de 1997. Regulamento técnico sobre as condições higiênico-sanitárias e de boas práticas de fabricação para estabelecimentos produtores/industrializadores de alimentos. Diário Oficial da União. 01 ago 1997. 